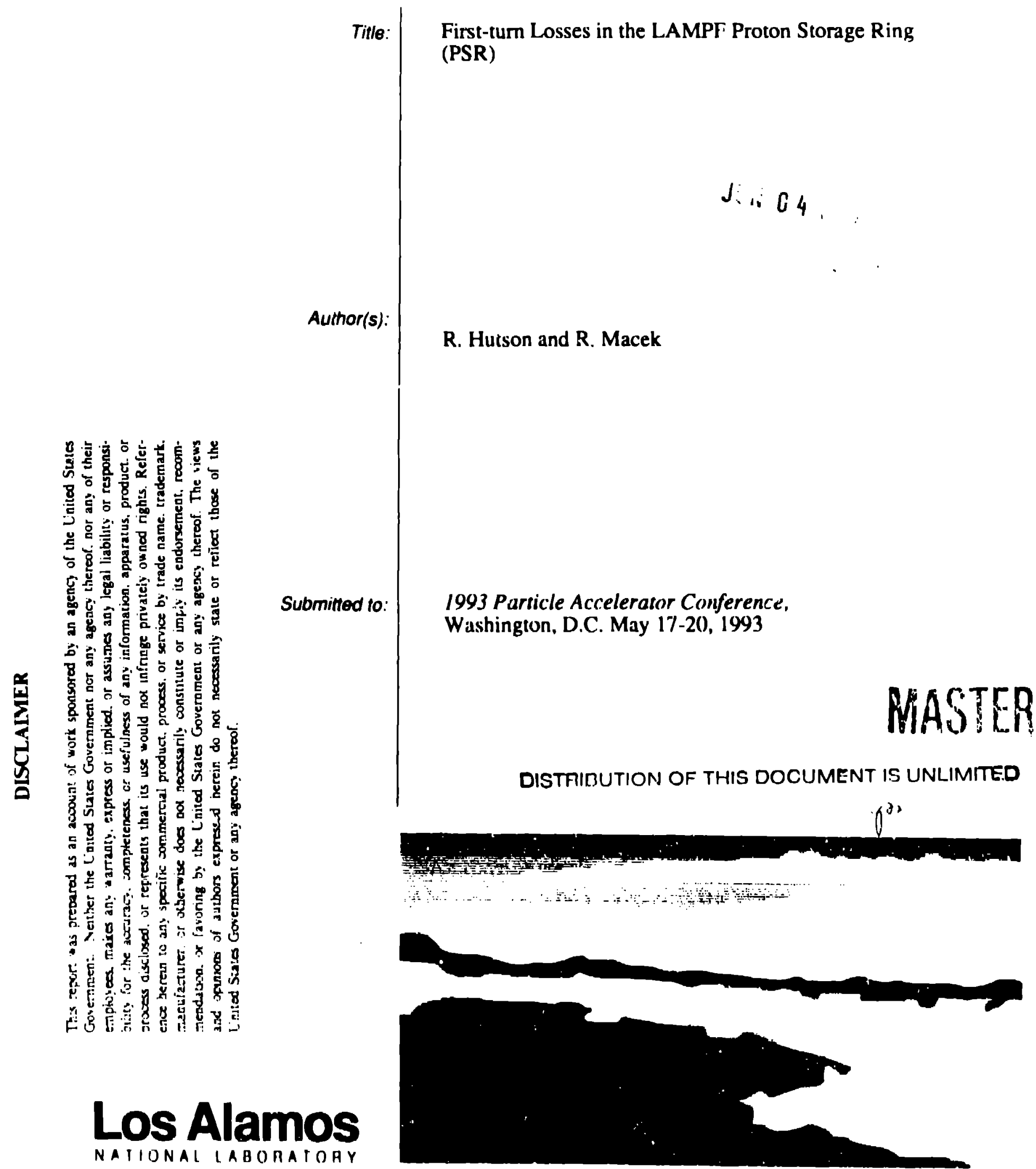

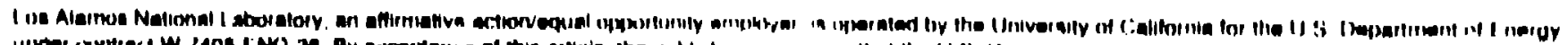

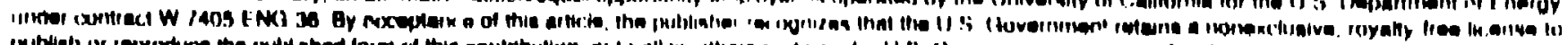

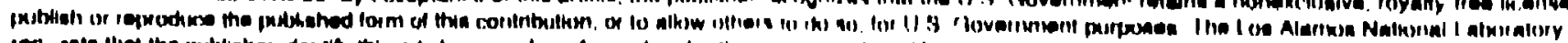

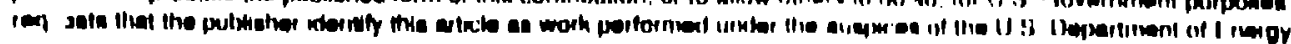




\title{
First-Turn Losses in the LAMPF Proton Storage Ring (PSR)
}

\author{
R. Hutson and R. Macek \\ Medium Energy Physics Divisıon, Los Alamos Natunal Laboratory, Los Alamos, New Mexico 875.5 LSA
}

\section{Ahstract}

Beam-loss measurements indicate that $0.2 \cdot 0.3 \%$ of the protons injected into the PSR are lost during the first turn. We describe a plausible mechanism, involving field stripping of excited hydrogen atoms, for these losses. Protons are injected into the PSR by transporting a neutral hydrogen heam through a hole in the yoke of one ring bender and then through a carbon foil on the nng axis. The foil strips roughly $93 \%$ of the beam atoms to protons. Although the original PSR design assumed that all unstripped atoms would pass through a hole in the yoke of the next downstream bender and on to a bearn stop, recent calculations [1] indicate that about $6 \%$ of these unsurpped atoms will emerge from the foil in an excited state with principie quantum number $n \geq 3$. These calculations also indicate that atoms in excited states with $n \geq 3$ will be stripped quickly to protons in the 1.2-Tesla field of the downstream bender. The trajectories of these protons will bc outside the phase-space acceptance of the ring and will be quickly lost by collision with the heam pipe. thereby giving rise to first-lum losses. The estumated numbers of protons that would be lost by this mechanism are consistent with the observec first-turn loss rates. This mecharusm has important consequences for the design of future sturage rings that use neutral atom or negative ion stripping for injection.

\section{INTRODUCTION}

Minimization if beam losses is a major goal at the PSR. At the present iune the PSR operates with beam loss rates in the range $0.35-0.45 \mu \mathrm{A}$, just below $0.50 \mu \mathrm{A}$, at which level radioactivation of ring components by the $800-\mathrm{MeV}$ beam hegins to make hands-on maintenance unreasonably difficult. Therefore, any reduction of loss races is highly desirable for mitigation of maintenance problems, and because it would permit raising the average besm current injectod into the ring.

Many of the development experiments done at the PSR have been aimed at furthering understanding of the mechanisms that cause boum lows. Two major classes of loss aicur: slow losses that would, if acting alone, result in a circulating beam lifetime of thousands of turns; and first-iurn losses in which a significant fraction of the injected beam is lost hefore making one complete revolution around the ring Slow losses have heen understoud for some time (2). They represent the loss of a small fraction of the total circulating beam for each revolution around the ring. Only recently has there emerged a convincing hypothesis to explain the cause "I lissl-tum losses This paper discusses the new hypothesis.

\section{MEASUREMENT OF BEAM LOSS}

Heam losses in the PSR are measured with a system it ien loss monitors licated around the onter periphery it the
PSR tunnel. The loss monitors ate liquad sinullatur tilled cans coupled to photomultiplier lubes. Figure ! hous a typucal heam loss rate pattern recorded durmg an interval spanning approximately $600 \mu$ s of heam injectuon followed hy a 100 - $\mu$ s period during which the beam is allowed (1) cilust without injection of additional beam. There are (wo) components to this loss signal. One is a measure of the slow loss rate. It is proportonal to the amount of heam circulating in the ring and increases linearly with tume. The other component is a measure of the first-turn loss rate. and is constant during injection because protons are heing injected at a constant rate. This component drops to zero at the end of injection

The 1 al heam loss is proportional to the tutal area under the curve thile the first-turn loss is proportional to the area under constant-width band at the top of the curve. There is a horr spike in the loss rate associated with the extraction of the circulatung: heam from the ring.

Total beam losies are typically $0.6-0.7 \mathrm{mo}$ of the amount if heam injected into the PSR with first-turn lowic: contrituung $0.2 \cdot 0.3 \%$ to this total.

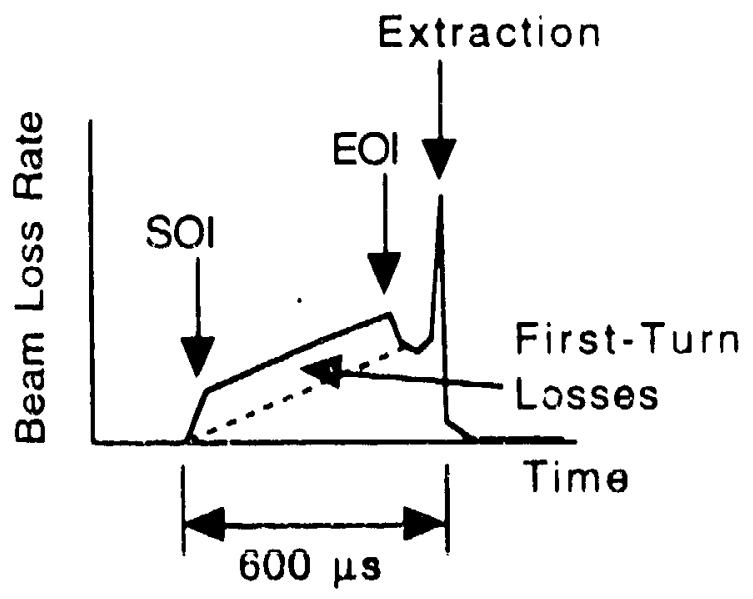

Figure 1. Beam Losses as a Function of Time Durung and for $I(x)$ us After the End of Injection (SOI = start of imleciunn. $\mathrm{IOOI}=$ end of injection)

\section{III. $\mathrm{H}^{+}$INJECTION INTO THE RINC;}

An understanding of the new hypothesss about the umgun if first-turn losses is helped by a brief description of the pricess by which protons are injected into the PSR is illustrated in Figure 2, 800-MeV H- ions are stripyed in $\mathrm{H}^{\prime \prime}$, in a I X. Tesla stripper magnet upstream of the ring. The $11^{\prime \prime}$ s iten enter the ring through hole in a ring dipole maguet in the ring. $H^{\prime \prime}$ s are stripped to protons by a $2(x)-\mu \mathrm{g} / \mathrm{c}^{2} \mathrm{~m}^{2}, \mathrm{uh} h \mathrm{~h}$ 1.11 lixated on the ring axis, and the protons then (1) 11 ille in the eing 
For each PSR pulse. protons atre injected at a constant rate for typically 1675 turns or $600 \mu \mathrm{s}$. At the end of injection the circulating proton bunch is extracted and transported to the spallatuon neutron target at the Los Alamos Neutron Scattering Center "ANSCF.

Approximately $7 \%$ of the incident $\mathrm{H}^{0} \mathrm{~S}$ that hit the $2(0)$. $\mu \mathrm{g} / \mathrm{cm}^{2}$ foil pass through without heing stripped to $\mathrm{H}^{+} \mathrm{s}$. Most continue undeflected by magnetic fields, and pass out through a hole in the yoke of the downstream dipole magnet and on 10 a heam stop. However, some exit the foil in excited atomic states and are stripped to $\mathrm{H}^{+}$in the downstream dipole.

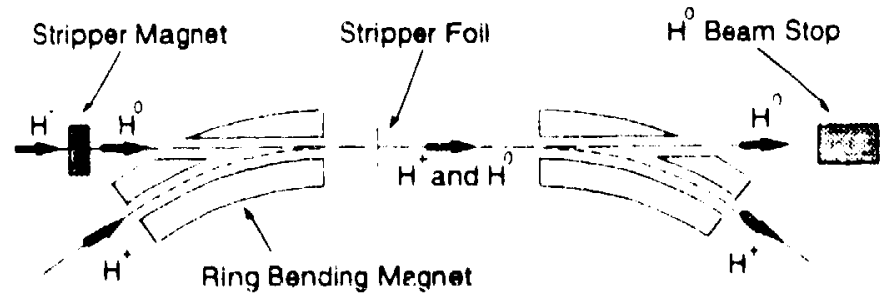

Figure 2. Beam Injection into the PSR

\section{THE MECHANISM OF EXCITED H ${ }^{j}$ FORMATION AND PSR FIRST-TURN LOSSES}

\section{A. Iniroduction}

Our conjecture is that the presence of excited state $\mathrm{H}^{(0)}$ emerging from the stripper forl is the root cause of first-turn losses in the PSR. Other work $13 \mathrm{j}$ has shown that when 80() . $\mathrm{MeV} \mathrm{H}^{-}$s pass through thin carbon foils, there are significant numbers of $\mathrm{H}^{0} \mathrm{~s}$ that emerge from the foil in an excited atomw state. In these $\mathrm{H}^{0} \mathrm{~s}$ the electron is relatively weakly hound, and some higher states will he susceptible to field stripping from the atom in the 1.2-Tesla field of the ring dipole magnet downstream of the stripper foil. Field stripping of $8(\%)$ - MeV excited-state $\mathrm{H}^{-}$ions in magnetic fields was demonstrated in earlier experiments [4]. The same processes will oxcur when ground-state $H^{(0)}$ s pass through foils.

\section{Simple Theory of Excited-State $H^{(0)}$ Formation and Firld Sitripping}

In a simple picture of excited $H^{(0)}$ formation, when an $Y(x)$. $\mathrm{MeV}$ ground-staie $\mathrm{H}^{()}$or $\mathrm{H}^{-}$enters a foil, the electron (1, electrons! is stripped from the proton, hut continue in near proximuty to and at the approximately same speed as the resulting proton. There is a significant probahility that an electron will be recaptured into an excited $!^{\circ}$ state hec ause the electron(s) and the proton remnin relatively neur ench other in their passage through the remaining licickness of foul Since. in the case of $\mathrm{H}^{0}$ stripping. there is inly ane electrot following the proton, instend of $(w 0)$ as in the case of 11 stripping. It is plausible (1) assume that the number of exciled state $\mathrm{H}^{0} \mathrm{~s}$ formed from $\mathrm{H}^{0}$ heams will be about ball the number formed from ll hemus.

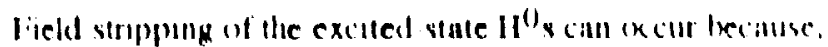

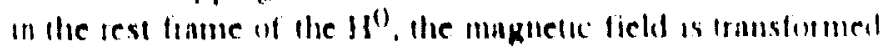

in part to an electric field that disiorts the afomic putential well. If the distortion is large enough. electrons in the hether excited states escape. Simple calculatons [i.5] indude that electrons in energy levels with principle yuantum number at about three and above are unbound and will he strapped a a 1.2.Tesla tield. Fegure 3 k an appreximate representathon it the polennal well tor an $\mathrm{x}(0) \mathrm{M} \cdot \mathrm{V} \mathrm{H}^{(1)}$, hoth in rero ficld and m a 1.2.T m.tenetic ficld.

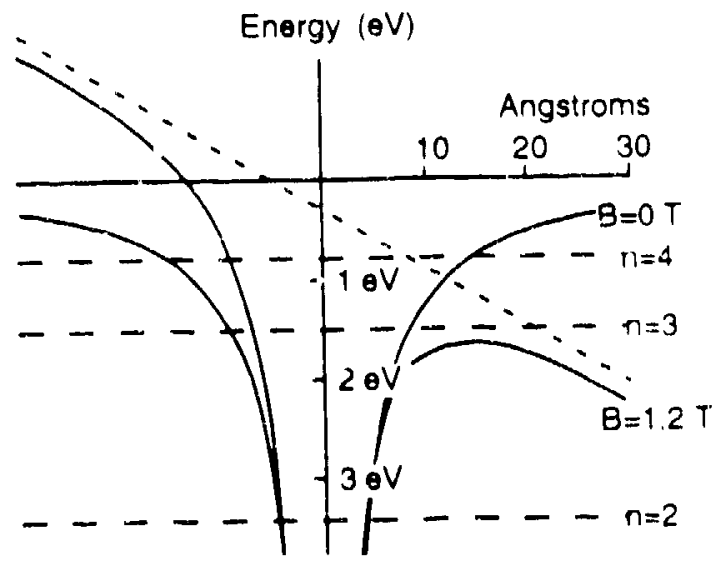

Higure 3. Hydrogen Alom Potential Well Disturtun lin $x(x)-\mathrm{MeV} \mathrm{H}^{(0)}$ in a 1.2 -Tesla Magnetic Ficld

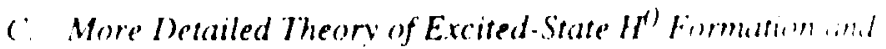
Fic'ld Sipriping

Damburg and Kolosov [6] give a more prese 11 anment

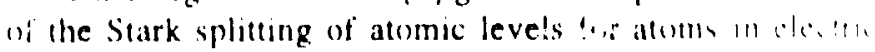
fields (or, equivalently, energetic atoms movms: thr. ath

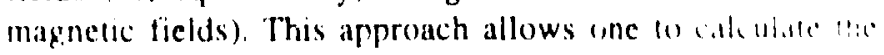
energy levels and widths, and therefore the lufermin it

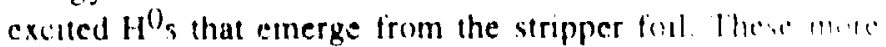
precise calculations indicate that there are elcotrom 111 . 111. with $n \geq 3$ that will be stripped in the dipule mlathe: downstrcam of the forl.

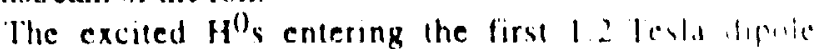
downstream of the PSR fonl will have finte lifetume in the field and will. therefore. penetrate part way mon the $110 \% 1$ region before heing stripped (1) protons. lintil the se stripped, the $\mathrm{H}^{()_{s}}$ will not tollow the same trajectirles an will

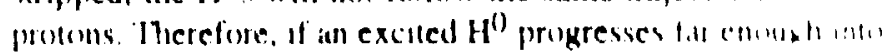
the magnet before stropping. 11 will mol be within the fithes space acceptance of the ring, and will he last an the vile e. I

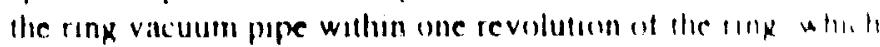
will cause first-lurn losses. This process 1 Illunllatid schematically in !igure 4.

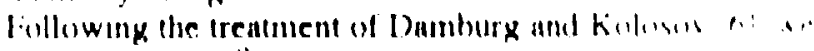
find that there are $f^{()}$states with pronciple guantum numbers 11:1 and n-4 that stron in the dipole field, hut hall hor i....

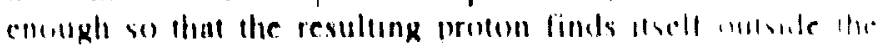
phise space aneplance af the rils

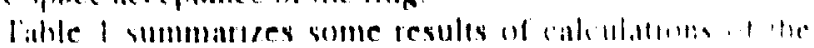

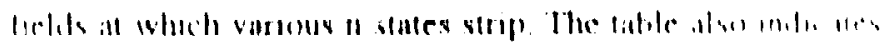

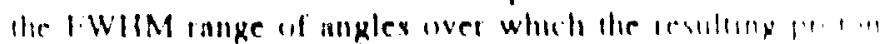

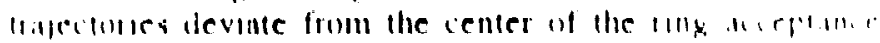

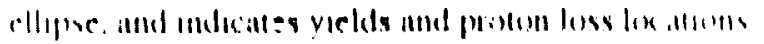




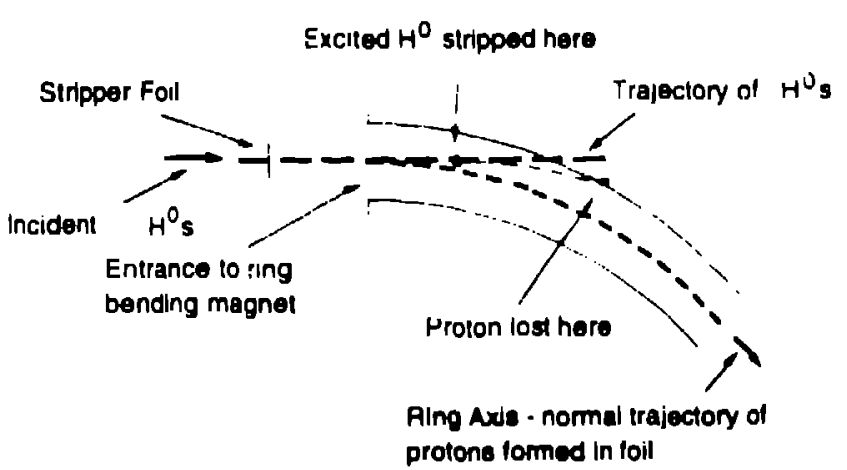

Figure 4. Schematic Illustration of the Process by which Excited $\mathrm{H}^{0} \mathrm{~s}$ Give Rise to First-tum Losses

Table 1. Angular displacement and loss location in ring of protons from stripping of various $n$ states of $\mathrm{H}^{0}$ and estimated yield of the $n$ states

\begin{tabular}{|c|c|l|c|}
\hline$n$ & $\begin{array}{c}\Delta \theta \text { range } \\
\text { (mradians) }\end{array}$ & Loss location in the ring & $\begin{array}{c}\text { Estimated yield } \\
\text { from } 200-\mu \mathrm{g} / \mathrm{cm}^{2}\end{array}$ \\
\hline 3 & $22-50$ & in first dipole & $0.30 \%$ \\
\hline 4 & $6.1-12$ & $\begin{array}{l}\text { after first dipole but in } \\
\text { the next 3 ring sections }\end{array}$ & $0.20 \%$ \\
\hline 5 & $1.8-4.4$ & $\begin{array}{l}\text { small fraction lost on } \\
\text { ring limiting aperture }\end{array}$ & $0.15 \%$ \\
\hline
\end{tabular}

- $\mathrm{I} / 2$ of measured yield from $\mathrm{H}^{-}$on $200-\mu \mathrm{g} / \mathrm{cm}^{2}$ carhon foil

Figure 5 shows the horizontal-plane ring phase-space acceptance ellipse and the $\mathrm{H}^{0}$ beam ellipses at the entrance to the dipole downstream of stripper foil. As an example. the range of angles, laken from Table 1 , over which protons from stripped $n=4$ states are distributed is indicated.

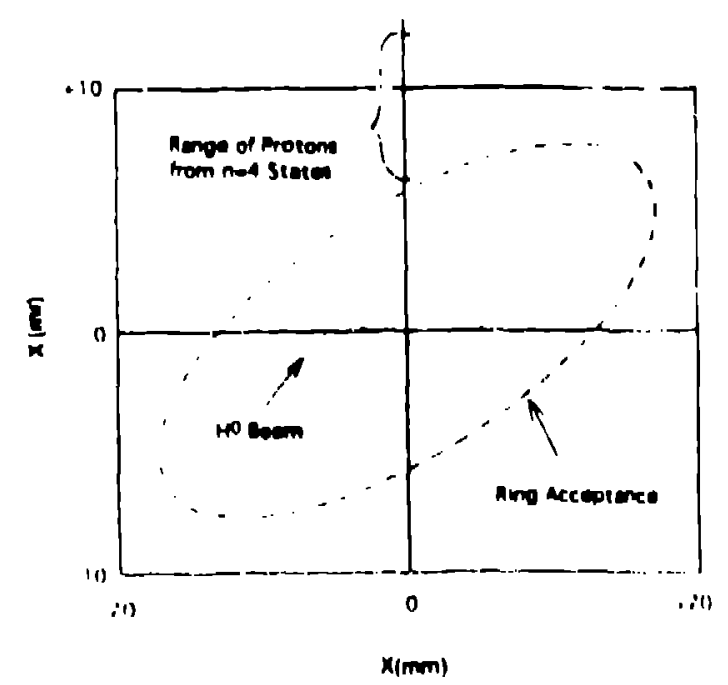

Higure S. Horizonlal plane Ring Acceptance and Incident II" Iream l'hase-space lillipses nt the V:ntrance (1) the I)ipule Magnet lownstream of the Siripper lioil
For high n states, lifetumes are shon and strupping ociurs so early in fringe field of the magnet that the resulting protuns follow essentially the same trajectorles that protons formed in the foil do. For $n=1$ and $n=2 . H^{(0)}$ states are no! stripped und conunue on to the $\mathrm{H}^{0}$ beam stop.

\section{DISCUSSION OF RESLLTS}

\section{A. Comparison of Measured and Estimated First Turn Losse's}

Experiments [7] have shown that approximately $0.50 \%$ of 800-MeV H's incident on a $200-\mu \mathrm{g} / \mathrm{cm}^{2}$ PSR stripper foil are converted to $\mathrm{H}^{0} \mathrm{~s}$ in the $\mathrm{n}=3$ state. Following the plausibility argument of section IV.A., we estimate that approximately $0.25 \%$ of the ground-state $\mathrm{H}^{0} \mathrm{~s}$ incident on the foil are converted to $\mathrm{H}^{0}$ in the $\mathrm{n}=3$ state. Assuming that first-lurn Iosses originate primarily from $n=3$ and $n=4$ states. and using the yields presented in Table 1, we estimate that the fitst-turn Insses should he approximately $0.4 \%$ of the total $\mathrm{H}^{0}$ heian incident on the foil. This is somewhat larger than the $037 \%$ observed with the loss monitors. However, since a lirge fraction of the first-lurn losses occur inside the first dipole downstream of the foil, the loss monitors will he shiclded from the beam spill point by the steel of the magnet. anil will provide an underestimate of the actual losses.

\section{H. Conclusions and Discussion}

We conclude that the estimated losses are consistent with the measured values, and interpret this fact as support fir the hypothesis that excited-state $\mathrm{H}^{\mathrm{S}}$ are the cause of the luster

Since new high-intensity proton storege rings houls: designed or contemplated involve $\mathrm{H}^{-}$ion injecusn hrough stripper foils, recognition and careful comsideralion if the consequences of the formation of excited $\mathrm{H}^{\mathrm{O}_{\mathrm{S}}}$ is import.unt fir the understanding and control of beaun losses.

\section{REFERENCES}

[1] J. Macek, private communication.

12] R. Macek ef al, "Analysis of heam losses at ISKR." Conference record of the ISRA EPAC Conferemir. Vill :lip. 12.52-1254.

[.3) A. Mohagheghi et al, "Interuction of relativistuc II IIII) with thin foils," Phuv. Rev. A, Vol. 4.3, INo. 1, pl' 19.45 1.365 (1491).

[4] T'. Bergeman ef al, "Shape resonances in the hydronen Stark effect in fields up to $3 \mathrm{MV} / \mathrm{cnu}, "$ l'his. Rer. l a't. Vol. 53, No, R, Pf). 775 - 778 (14M4).

[.5] (hihiro Ohmon, private communcation.

(B) R. Damburg and V. Kulosov. "Theoretical stludices hydrogen Rydberg Htonis in eleciric tields'" in KJubsiz stmes of nown and molecules, edited hy R. Sirbhinks, inl I: Lunning (Combridge Uaiversity Press, C'amburlpe. 10k31, 31. 31 - 71 .

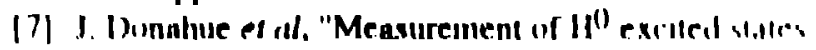

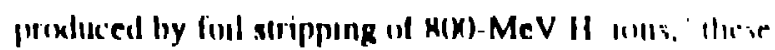
prixecdings. 